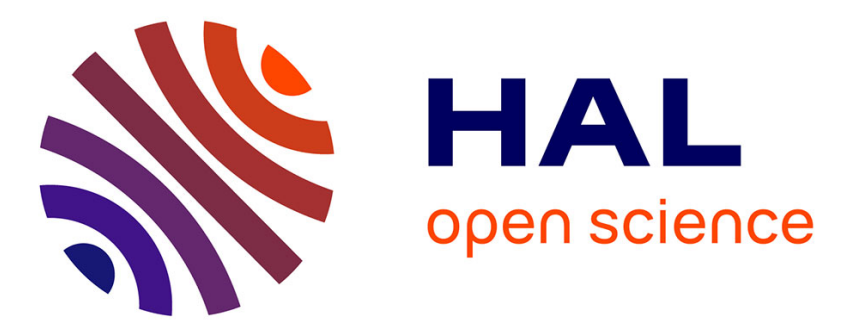

\title{
Digitized Residential Address System: A Necessity Towards the Faster Service Delivery and Smart Cities Development in India
}

\author{
Harish Kumar, Manoj Kumar Singh, M. P. Gupta, J. Madaan
}

\section{To cite this version:}

Harish Kumar, Manoj Kumar Singh, M. P. Gupta, J. Madaan. Digitized Residential Address System: A Necessity Towards the Faster Service Delivery and Smart Cities Development in India. 16th Conference on e-Business, e-Services and e-Society (I3E), Nov 2017, Delhi, India. pp.434-441, 10.1007/9783-319-68557-1_38. hal-01768506

\section{HAL Id: hal-01768506 \\ https://hal.inria.fr/hal-01768506}

Submitted on 17 Apr 2018

HAL is a multi-disciplinary open access archive for the deposit and dissemination of scientific research documents, whether they are published or not. The documents may come from teaching and research institutions in France or abroad, or from public or private research centers.
L'archive ouverte pluridisciplinaire HAL, est destinée au dépôt et à la diffusion de documents scientifiques de niveau recherche, publiés ou non, émanant des établissements d'enseignement et de recherche français ou étrangers, des laboratoires publics ou privés. 


\title{
Digitized residential address system: A necessity towards the faster service delivery and smart cities development in India
}

\author{
Harish Kumar*, Manoj Kumar Singh, M.P. Gupta and J. Madaan \\ Department of Management Studies, Indian Institute of Technology, \\ IIT Delhi, New Delhi 110016, India \\ harishkr08@gmail.com, manojksietegmail.com, \\ mpgupta@dms.iitd.ac.in, jmadaan@dms.iitd.ac.in
}

\begin{abstract}
The Economic development of the country also depends on its IT enabled services available to common citizens. The cost effective services, delivery mode and delivery time make the governance friendly to the citizens. But the conflicting and lengthy house's address system in India causes a lot of delays in services delivery. A house or building address could be used for various purposes like postal services, courier services, logistics services delivery, meetings, party venue etc. A high degree of failed service deliveries provide a gap to digitize the house address system to deliver accurate and faster services to the citizens. The paper proposes a conceptual method to digitize the house address system which may be stored electronically into a centralized database to reduce the time consuming process of writing and storing a lengthy address repeatedly for delivering the various services. The paper also explores the possibilities of how this digitized address could be integrated with the aadhaar database system to make it more potentially applied in terms of citizens' oriented applications and services. The digitized address would contribute significantly to transform India into a digitally empowered society and knowledge economy.
\end{abstract}

Keywords: Digitized residential address. Smart city. Faster services. Digital India. Aadhaar card.

\section{Introduction}

The variety and quality urban services [5] lead to social and economic sustainability of urban living [17]. The smart cities are defined as ICT based cities which have a promise of providing better services and quality of life to its citizens. The development of physio-socio-digital infrastructure in the cities are the base condition for the smart cities program. The government of India has taken a lot of initiatives to digitalize the city data, information and infrastructure like digital India campaign, digital India platform, and open data platform to innovative, quality and timely services and efficient delivery of services to its citizens. To digitize the services, web2.0, mobile platforms, cloud, aadhaar and payment gateways can be integrated. A lot of difficulties usually being faced by city governments while planning for the city development [3]. A home or building address can be used for administrative, emergency response, marketing, GIS, routing and navigation, and many other purposes and services. The information based services $[3,11]$ must be focused of the smart cities infrastructure which provide opportunities to make cities digitally empowered. The 
success of digital address program will stands India as a leading nation in terms of developed and advanced facilities.

\subsection{Digital initiatives to make digitally empowered country}

Digital India initiatives are preparing India to become a knowledge economy and digitally empowered country through synchronized and coordinated engagement of the all levels of the government. A digital government can be defined as regular patterns of growth in a particular country [8]. The Digital India campaign primarily focuses on the inclusive growth of use smart devices, facilitating electronic services, products, manufacturing and job opportunities etc. The program also includes the development of digital infrastructure in the country. The digital government landscape shows the government initiatives to innovate and provide digital solutions to social, economic, political and other pressures [8]. The increasing population and high demand of services have created pressure on government and logistics supplier to deliver the services in a fast and accurate manner. The government is trying to integrate services across various departments to pace the service delivery speed with in the city and across the cities. The trust, security, privacy, accessibility and quality of public services are some of the major issues [7] in providing e-services to the citizens.

The cloud computing, big data, ICT applications and smart devices have created the platform for digitally empowered citizens. Access to services, quality of services, information privacy and security could be enhanced through cloud solutions. Some policy initiatives have been undertaken by government of India like e-kranti framework for electronic delivery of service, e-infrastructure for delivery of e-services, policy on adoption of open source software, policy on use of IT resources, collaborative way of development, use of cloud big data, securing India's cyber space, knowledge network to enhance India's role in global platforms of internet governance and service deliveries.

\subsection{Service delivery system in cities}

The high rate of urbanization and increasing population worldwide are creating a huge pressure on city infrastructure and services. The cities are competing each other to attract resources, cultural advancements and increased quality of life [9, 14, 19]. There is a lot of pressures on service providers to meet the service demand and delivery of the services at right time. The growing volume of packets, mail, increasing competition from private courier industry, administered prices, poor technology [16] and confusing addresses are some main causes for the failures, lost and delays in services [6]. Usually, the service providers are unable to locate the lengthy, conflicting and unorganized addresses provided by citizens, resulting inefficient government and commercial service deliveries [6]. The growing rate of urbanization creates a lot of confusion to locate the exact address to deliver the critical urban services. The personalization of the cities [11] can be done to improve the efficiency of their local services. 
The smart cities are defined as ICT enabled cities which would provide the high quality services, improved life styles and happy living to its citizens. The smart city transformation would enhance the communication among citizens, government and service providers that may require the changes in city operations, including government, buildings, mobility, energy, environment and services. The main focus of smart cities development are to fulfill the needs of citizens, providing local services, and digital infrastructure [3]. The delivery of services accurately, quality of services and time consumed in service delivery could be main focus of service providers in smart cities. For that house or building needs a digital address that could be integrated with smart technologies like internet of things (IoT) devices, smart phones and cloud applications. To manage the digital addresses city wide or country wide, a centralized address database would be needed. Whenever a person uses digital address, the database should decode the complete physical address of the same. The address intelligence [18] can be used for area-specific solutions to increase the timely service delivery. The innovative planning, implementation of policies and some regulations are required [16] to design the digital address to make Indian society completely digital in terms of services.

\section{$2 \quad$ Literature studies}

The cities and societies which have future vision and advanced development plan tend to show better economic and societal health [10]. The governments are adopting the new technological solutions to respond the current pressures [8] of service demands and to provide services for all the citizens in a hassle free environment. The digital India campaign will promote e-governance and Indian economy to a new heights in near future. Easy access to public services, cashless transactions and smooth service delivery would develop a digitally advanced societies and cities in India. The role of governance have been signified $[10,12]$ in improving the various services provided to citizens. A huge range of information and services [7] can be provided online through e-government and mobile government. The services provided by government should be based on the demand and requirement of its citizens which would help government to improve its accountability and responsibilities [13] towards the citizens. Citizens' perceptions and participation should be considered while developing new services. ICT [1] can alter the way individuals, organizations, and governments usually works. Implementation of ICTs can improve quality of life for citizens especially living in the less developed countries [2]. The use of ICT has been vastly promoted [13] in government in last few years. It has been found that managing a coherent address system can be difficult for a city government even under the best circumstances [6]. A lot of frauds [8] have been reported related with failed service deliveries in the cities which causes insecurity among the citizens to use digital services and putting orders online. The validation is required for the correctness of the mentioned place before start delivering the service. The address validation techniques should be implemented to check for consistency among address components and corrects them [16]. The provided address further cross checked for any inconsistency or mis-spelt. Therefore, to deliver the services to its citizens in a proper fashion, a digital address system is required. 
In previous studies performed in various countries, the street address was main concern while designing the house or building addresses. Street was divided into primary, secondary, and third order streets based on use and importance [6]. Some streets were categorized into even and odd number streets and number usually increases towards the moving direction from the reference point [6]. The most important street normally gets the most important name. Some authors have used directional conventions in designing the address systems. But now a days, this type of addressing system cannot be deployed. The feature address might have any syntax, but city, state, and pin code were separated from the rest of the address. House address must be applied effectively to inform to the public especially to the children. Naming convention should be proposed for the new developments at the time of developing sector layouts in a particular city. If a person feed digital address string, the exact and verified location should be shown correctly. Thus, the integration of national digital address system database with GIS and aadhaar database will solve such issues and would promote automation in addressing system.

\section{Proposal for the digitized address system}

The effective use of technology is the need of this competitive era in terms of development and modern infrastructure. ICT has totally changed the way of living in urban as well rural areas. The smart digital address could be a combination of technology, information and data to make digital infrastructure and better delivery of services. Assigning and management of buildings address could be done via digital address system. A house or building address usually contains house/building number, area name, city/village name, district name, state name, country name, pin code [16].

The paper proposes the concept of digitizing residential and commercial addresses. An address database should be developed to record and maintain all physical addresses. Whenever the digitized address string is used electronically or scanned, it would automatically show or print the complete address of that person or organization from the central address database (figure 1). This would also make the citizens smart to maintain an automated personal digital address book and fast accessibility to house services. The service and billing addresses might not be always identical. In such cases more than one digitized string can be used clearly indicating which one should be used for service delivery. 


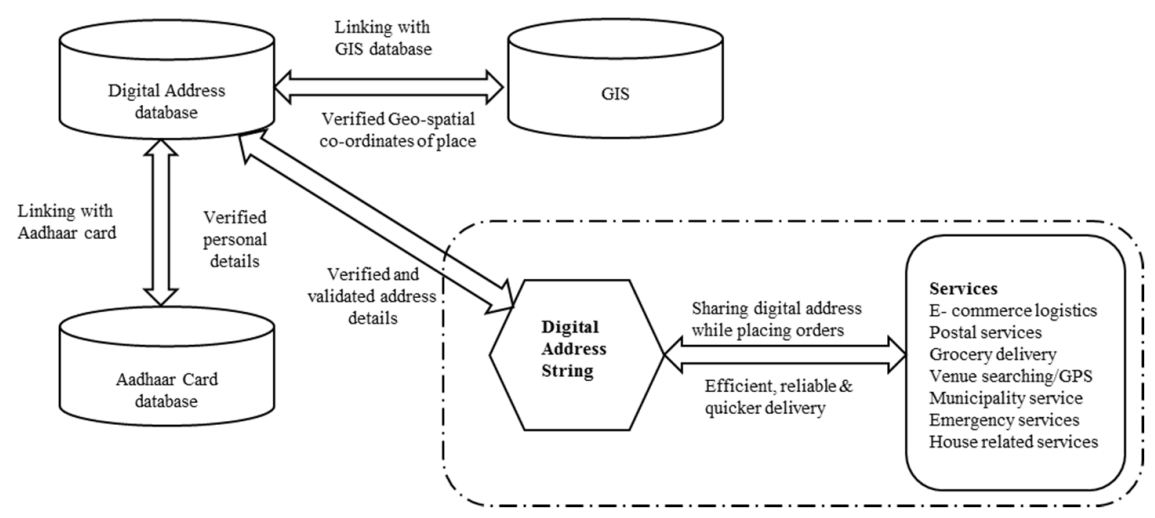

Figure 1. Service delivery using digital address system and linking digital address with Aadhaar card

The centralized digital address database could be linked with aadhaar card database. Integration of aadhaar card would provide biometric authentication, eKYC and verified address information (figure 1) to reduce the address frauds and confusions in services deliveries. Compulsion of providing Aadhaar number of sender (in case of courier/postal service) would give the auto-verification of person who wish to send the particulars. Requesting aadhaar number with digital sign of recipient at the time of service delivery would make the system more robust and will control the frauds. The digital address database can also be linked with GIS database to find the geospatial information of a particular address.

The residential or commercial address could be digitized into a string of alphabets and numbers like vehicle number, phone number, bank account number, passport number or aadhaar card number. Followings are some suggestions to design a digital address (table 1). The followings are the assumptions in proposed digitized residential address system-

1. Each city and village should be assigned a unique code or number in respective district (like Indian railway has given a unique code to all stations)

2. Unique pin code system (already exist in India which signifies region, district and postal office of a particular area)

3. Each sub locality, sector, colony, society or village area should be assigned a unique number by concern authority.

4. Each house/ building/ tower/ bhulekh/ plot number should be assigned a unique number (Most of the cities/village are already have this).

Table 1. The proposed guidelines for digitization of house address system

\begin{tabular}{|c|c|c|}
\hline Particular & Data type & Examples \\
\hline City code /Railway station code/ Tehsil code & String (4 digits) & For Ghaziabad - GZB \\
\hline
\end{tabular}




\begin{tabular}{|l|l|c|}
\hline Pin Code & Numeric (6 digits) & 201001 \\
\hline $\begin{array}{l}\text { Sub locality /sector/ colony/ village/society } \\
\text { code }\end{array}$ & Numeric (3 digits) & $\begin{array}{c}\text { Nehru Nagar }=067, \text { Sector 144= 144, } \\
\text { Shiv colony }=052\end{array}$ \\
\hline House/Building/ Tower/ Bhulekh/ plot number & String (4 digits) & House $=$ C073, Flat= Z401, Plot=0132 \\
\hline
\end{tabular}

Table 2. Example of a digital address

\begin{tabular}{|c|c|c|c|c|}
\hline Address particulars & City/Village & Pin code & Locality & House number \\
\hline $\begin{array}{c}\text { Current Address } \\
\text { system }\end{array}$ & Ghaziabad & 201001 & Nehru Nagar & C073 \\
\hline Digital Address & GZB & 201001 & 067 & C073 \\
& $\downarrow$ & $\downarrow$ & $\downarrow$ & House number \\
\hline & City/Village code & Pin code & Sector code & Humber \\
\hline
\end{tabular}

Thus from table 2, the digital address of House number C-73, Nehru Nagar, Ghaziabad, Gautam Buddha Nagar, India-21001 would be GZB201001067C073. The use of city/village code (as per Indian railway standard) will provide a better readability to the service providers in terms of understanding because a city code generally can be remembered easily as compared to interpreting the postal code digits or scanning the whole string to get the details every time. This would help in sorting and arranging order materials or delivery packets in city wise clustering during the transit. After city code, the pin code will provide the direction till to the post office of a locality. Then rest part of the string will direct the service provider till to the recipient. The locality could be further divided into sub section codes based on city/village's special requirements. If a particular is not applicable for some areas, in such cases, 00 could be assigned in digital string. If a village, society, town, city, district or state formed newly, the same standards should be follow in a regular pattern to digitize the new addresses. Whenever a person shifts from one address to another, the digitalized address must be updated with new address string in a centralized address database system. The address change may be notify to the contacts associated with the person's contact book. It might be optional alerts if a person wants to notify his new address to his relatives or known persons.

The hospitals, police station, fire brigade stations, army cant area, historically important area could be assigned a special code while digitizing their addresses to make them distinguished which could be navigate faster in an area with their special code.

\section{Benefits of digitized address system}

The residential digitized address system will have a lot of benefits like address standardization and faster navigation of any location. The digital address could be stored or scanned electronically for various service deliveries rather writing a lengthy address every time. Whenever a person feed this digital address string, global positioning system should also indicate the exact location physically. This system would reduce the address duplication efforts, resolving conflict and confusing addresses, 
improving the service delivery quality, quicker reach of emergency services, more efficient wide range service delivery, facilitating housing census, and would help ecommerce firms and government organizations to expend their services especially in tier-II and tier-III cities to make the lives of citizen easier and more comfortable in a digitally empowered era.

\section{Conclusions}

The house address system must be more consistent citywide as well as country wide. A digital address of a house or building would make address location simpler for residents and businesses. The digital address system would improve the navigation and search to find the exact location in cities or towns. The emergency services would response in a lesser time to deliver emergency services like health, fire, and resolving security issues. The digitized house address system will enhance the digital empowerment of citizens and collaborative digital platforms for participative governance with services, policies and best practices. The national digital address system will enhance the readiness of government to develop smart cities and digital empowered India.

\section{Limitations and further research}

The basic need for the digital address system will be high speed secure Internet. Setting up the broadband and maintaining Wi-Fi connectivity throughout the city and country is a big challenge to the government. Maintaining digital infrastructure with the advancement in technology, security and privacy of individual details would be crucial challenge for the concern authority. The digital divide [15] can affect the quality aspects of service accessibility and usability. The digital divide is a relative concept measuring the gap in access and use of ICT systems between individuals, groups and countries [4]. The government should take some initiatives to reduce digital divide among the citizens. The use of digital address would vary on age of citizens, geography, education level, language and physical disability of the citizens. The facility to write address and displaying address in Indian local language must be required to make the complete use of digital address system to highlights the transformative impact in citizens' life through digitalization. In the present study, we have not included details of a recipient like name, mobile number as we can see in current address system in India. To identify the recipient, the study has suggested to link address with aadhaar database. This would increase the complexity at digital infrastructure level. But by integrating this, a verified personal details and valid address will enhance the faster service delivery to the citizens. In future, a more holistic and generalized digital address system could be designed to make India a digitally empowered country in a real sense. 


\section{$7 \quad$ References}

1. Alawneh, A., Al-Refai, H., \& Batiha, K.: Measuring user satisfaction from eGovernment services: Lessons from Jordan. Government Information Quarter$l y, 30(3), 277-288$ (2013).

2. Ayanso, A., \& Lertwachara, K.: An analytics approach to exploring the link between ICT development and affordability. Government Information Quarterly, 32(4), 389398 (2015).

3. Belanche, D., Casaló, L. V., \& Orús, C.: City attachment and use of urban services: Benefits for smart cities. Cities, 50, 75-81 (2016).

4. Brännström, I.: Gender and digital divide 2000-2008 in two low-income economies in Sub-Saharan Africa: Kenya and Somalia in official statistics. Government Information Quarterly, 29(1), 60-67 (2012).

5. Gupta, M. P., \& Jana, D.: E-government evaluation: A framework and case study. Government information quarterly, 20(4), 365-387 (2003).

6. Infrastructure, G. S. D.: Street Addressing Standards and Guidelines for the State of Georgia (2000).

7. Jaeger, P. T.: The endless wire: E-government as global phenomenon. Government Information Quarterly, 20(4), 323-331 (2003).

8. Janowski, T.: Digital government evolution: From transformation to contextualization. Government Information Quarterly, 32(3), 221-236 (2015).

9. Jung, T. H., Lee, J., Yap, M. H., \& Ineson, E. M.: The role of stakeholder collaboration in culture-led urban regeneration: A case study of the Gwangju project, Korea. Cities, 44, 29-39 (2015).

10. Khalil, O. E.: e-Government readiness: Does national culture matter?. Government Information Quarterly, 28(3), 388-399 (2011).

11. King, S., \& Cotterill, S.: Transformational government? The role of information technology in delivering citizen-centric local public services. Local Government Studies, 33(3), 333-354 (2007).

12. Lee, H., Irani, Z., Osman, I. H., Balci, A., Ozkan, S., \& Medeni, T. D.: Research note: toward a reference process model for citizen-oriented evaluation of egovernment services. Transforming Government: People, Process and Policy, 2(4), 297-310 (2008).

13. Linders, D.: From e-government to we-government: Defining a typology for citizen coproduction in the age of social media. Government Information Quarterly, 29(4), 446-454 (2012).

14. Miles, S., \& Paddison, R.: Introduction: The rise and rise of culture-led urban regeneration. Urban studies, 42(5-6), 833-839 (2005).

15. Mutula, S. M.: Digital divide and economic development: case study of sub-Saharan Africa. The Electronic Library, 26(4), 468-489 (2008).

16. Nagabhushan, P., Angadi, S. A., \& Anami, B. S.: A Knowledge based Fast PIN code Validation System for Dispatch Sorting of Postal Mail. In International Conference on Cognitive systems New Delhi, 14th and 15th December (2004).

17. Neirotti, P., De Marco, A., Cagliano, A. C., Mangano, G., \& Scorrano, F.: Current trends in Smart City initiatives: Some stylised facts. Cities, 38, 25-36 (2014). 
18. Van Duin, J. H. R., de Goffau, W., Wiegmans, B., Tavasszy, L. A., \& Saes, M.: Improving home delivery efficiency by using principles of address intelligence for B2C deliveries. Transportation Research Procedia, 12, 14-25 (2016).

19. Zhong, S.: Artists and Shanghai's culture-led urban regeneration. Cities (2015). 